\title{
КРАТКИЙ ОБЗОР ДИАЛЕКТАЛЬНОЙ СИТУАЦИИ В ИТАЛИИ
}

\author{
Ю. В. Гаврилова \\ Московский гуманитарный университет
}

\begin{abstract}
Аннотация: В данной статье дается характеристика итальянского языка, его происхождения и основных фонетических, грамматических и лексических особенностей диалектов современной Италии. Диалектальное разнообразие в современном итальянском языке обусловлено историческими факторами, так как длительное время на территории Италии существовал ряд независимых государств. Приведены примеры диалектальных различий на уровне слов и целых предложений.
\end{abstract}

Ключевые слова: Италия; итальянский язык; диалект итальянского языка

\section{A SHORT OVERVIEW OF DIALECTS IN ITALY}

\author{
J. V. Gavrilova \\ Moscow University for the Humanities
}

\begin{abstract}
The author of this article provides a general overview of the Italian language, its origin and basic grammar, phonetic and vocabulary features of modern Italian dialects. The dialectal diversity in modern Italian is determined by historical factors, as for quite a long period of time there were several independent states on the territory of modern Italy. The article contains examples of differences between dialects in vocabulary and phrases.
\end{abstract}

Keywords: Italy; the Italian language; Italian dialect

Итальянский язык по праву считается одним из красивейших и «певучих» языков в мире. Многим, кто слышит итальянскую речь и не догадывается о значении слов, она кажется очень красивой и мелодичной. Специалисты объясняют это тем, что почти все слова заканчиваются на гласные, а также в целом наличием в словах большого количества гласных звуков. А те, кто уже приступил к изучению языка, как правило, с большим интересом это делают, так как фонетика итальянского во многом близка к русскому языку. Например, нет межзубных звуков или грассирующего звука «р». Итальянский алфавит имеет всего 26 букв, он самый короткий среди европейских языков. Обычно студенты достаточно быстро учатся читать по-итальянски. По некоторым данным, сейчас итальянский язык входит в топ-5 самых изучаемых языков в мире. Общее число говорящих на итальянском языке в мире составляет более 70 миллионов человек.

По классификации итальянский язык относится к группе романских языков индоевропейской языковой семьи, которые «берут своё начало от народной латыни, языка, на котором разговаривали жители Римской империи» (Рыжак, 2018: 9). Сейчас итальянский язык имеет официальный статус не только в Италии, но и в микрогосударствах на территории Италии Ватикан и Сан-Марино, а также, например, в Швейцарии.

Диалекты итальянского языка сформировались на территории Апеннинского полуострова ещё в средние века. На протяжении многих столетий имела место раздробленность. Так, например, на севере полуострова существовала Венецианская республика, на юге Неаполитанское и Сицилийское королевства. Как указывают 
авторы учебника по итальянскому языку Н. Рыжак и Е. Рыжак, знакомя учащихся с особенностями языка: «к концу XVIII века возросла роль Флоренции, Сиены и других городов центральной Италии региона Тоскана. Тоскана становится колыбелью культуры Возрождения. Тосканский диалект (или, иначе, флорентийское наречие), на котором создавали свои произведения великие Данте Алигъери, Франческо Петрарка и Джованнни Боккаччо, лёг в основу итальянского литературного языка. Языковая раздробленность в Италии не была преодолена даже после создания единого итальянского государства во второй половине XIX века (1861 год)» (там же: 9).

Алессандро Манцони, итальянский поэт и романист, также поддерживал флорентийский диалект и всячески продвигал идею о том, что именно он должен лечь в основу национального итальянского языка. В дальнейшем этот язык исторически развился в литературный итальянский и распространился по всему полуострову. Теперь уже и поэты из других регионов, такие как эмильянец Маттео Мария Бойардо в XV в. или неаполетанец Якопо Саннадзаро в XVI в., писали свои произведения на тосканском варианте итальянского языка. Однако, по сути, эта языковая раздробленность сохраняется и сейчас.

Местные наречия сильно отличаются от общепринятого литературного языка и настолько не похожи между собой, что северянин и южанин никогда не поймут друг друга, если каждый из них будет говорить на своём диалекте. Диалектальные различия в итальянском касаются лексики, грамматики, произношения.

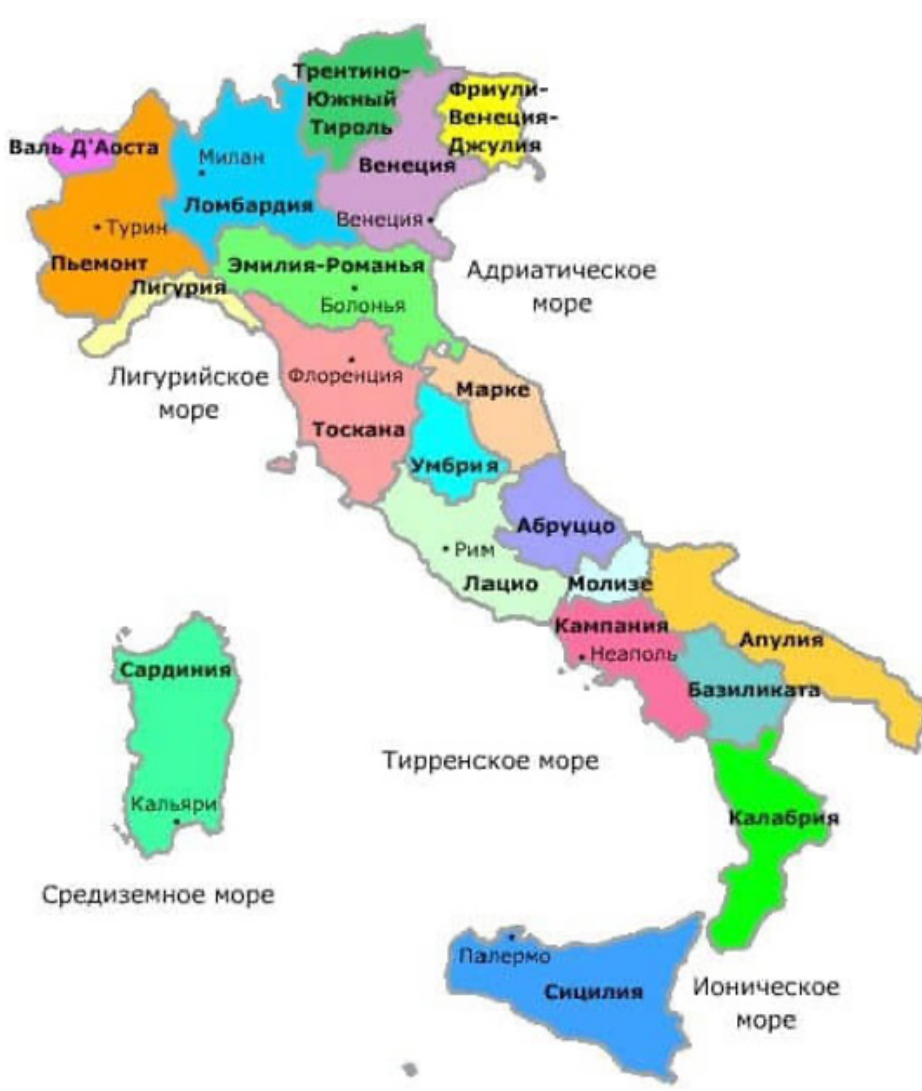

Рис. 1. Регионы Италии (Источник: https://emigrating.ru/ wp-content/uploads/2019/05/4-2.jpg)

Fig.1 Italian regions (Source: https://emigrating.ru/wpcontent/uploads/2019/05/4-2.jpg)

Диалект Рима, романеско, наиболее близок к литературному языку. В основном отличия между романеско и литературным языком наблюдаются в произношении, некоторые звуки видоизменяются илипроглатываются. В плане лексики особенностью является то, что в романеско активно используются ругательства, они не запрещены. Сначала римское наречие было ближе к неаполитанскому, но с XIV в. ситуация изменилась благодаря общему процессу «тосканизации».

В целом же диалекты делятся на группы по территориальному признаку. На рис. 1 представлена карта регионов Италии.

Группа № 1. Североитальянские диалекты. Север Италии относят к галло-романским диалектам (или галло-итальянским). В небольшой области Валле-д'Аоста (Valle d'Aosta) на северо-западе, граничащей с Францией и Швейцарией, помимо итальянского, официальный язык также французский, жители обща- 
ются на своем коренном франко-провансальском диалекте и окситанском языке. Регион Пьемонт (Piemonte) использует в общении пьемонтский диалект. На нем говорят около 2 миллионов человек. В регионе Венето (Veneto) на северо-востоке и на всем северном побережье Адриатического моря используется венетский диалект, что сложилось исторически, в связи с политическим и культурным развитием Венеции. Значительная часть итальянцев севера живет в Ломбардии (Lombardia) со столицей в Милане - богатой и развитой северной провинции. На ломбардском диалекте говорит около 10 млн человек. Ломбардский язык занимает второе место по распространённости после итальянского. Воображаемая линия Специя-Римини отделяет северные диалекты от южно-центральных.

Группа № 2. Центральные диалекты. К центральной части Италии относят: Тоскану (Toscana), где говорят на тосканском диалекте; Умбрию (Umbria); Марке (Marche); Лацио (Lazio), где центром является Рим с соответствующим наречием романеско, о котором речь шла выше. На юге региона распространен неаполитанский язык. Регион Тоскана (Toscana) знаменит своим классическим итальянским. Отсюда началось лингвистическое объединение регионов. Сейчас каждый итальянец независимо от региона проживания учит два языка - литературный итальянский и «свой», чтобы уметь общаться в своей провинции. Тосканский диалект имеет свою особенность в произношении. Например, тосканцы не произносят букву «к», она у них звучит, как «х», поэтому слово casa [каза] (дом) здесь может звучать как [хаса].

Иногда другие классификации могут выделять тосканские диалекты в центре (среди них основной флорентийский), а остальные диалекты относят к южно-центральным (Умбрия, Марке, Лацио).

Групnа № 3. Южные диалекты.

Южные области

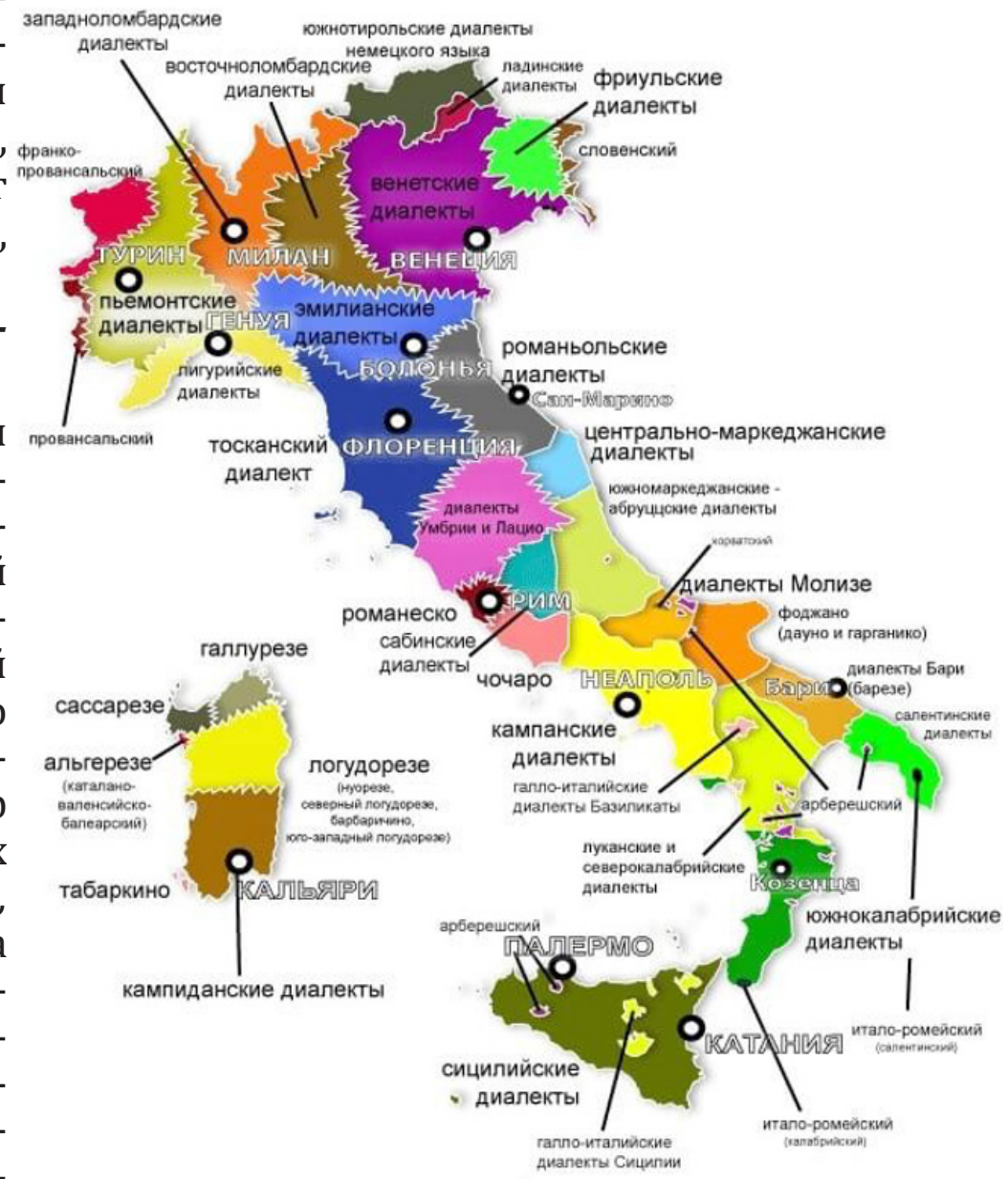

Рис 2. Диалекты Италии (Источник: https://emigrating.ru) Fig.2 Italian dialects (Source: https://emigrating.ru) 
В 2008 г. Региональное правительство Кампании официально провозгласило неаполитанский полноценным языком. Это было сделано для того, чтобы защитить язык, продвигать его изучение, а также сохранить местную культуру и традиции. В неаполитанском языке довольно заметны грамматические различия, например, наличие существительных среднего рода, тогда как в литературном языке грамматически только 2 рода, мужской и женский. На самом юге страны, в Калабрии (Calabria) и на острове Сицилия (Sicilia), разговаривают преимущественно на сицилийском диалекте. Отдельно выделяют лингвистическую ситуацию острова Сардиния (Sardegna). Местный язык представляет собой смесь разнообразных итальянских наречий, точное число которых до сих пор не установлено. На карте можно увидеть более подробные сведения о диалектах.

Ниже приведём несколько примеров интересной разницы в диалектах. Слово «улица» переводится на итальянский как via, но существует около 400 слов, употребляемых для разной передачи слова «улица» на диалектах:

- В Вероне это regasta;

- В Мантуе - spalto;

- В Венеции - calle;

- В Падуе - riviera;

- В Неаполе - сира.

«Мальчик» - ragazzo в классическом итальянском языке, а в Риме - ragà, в Неаполе-guaglione. Обычноепредложение «мыприезжаем», котороев итальянском звучит как stiamo arrivando, в венецианском диалекте - sémo drio rivàr.

Чтобы представить себе разницу между диалектами итальянского и его литературным вариантом на уровне целых предложений, приведем в пример пословицы и поговорки, употребляющиеся на диалектах в разных регионах Италии, в сравнении с итальянским литературным вариантом языка. В каждой паре фраз вторая приведена на литературном. Примеры взяты с сайта http://www.liveitaly.eu.

\section{Пьемонт:}

Par paghè e mori j'è sempar temp.

Per pagare e morire c'è sempre tempo.

Заплатить и умереть - время всегда найдется.

A ten l'anima cui dent.

Tiene l'anima coi denti.

Он держит душу зубами (о людях со слабым здоровьем).

\section{Ломбардия:}

La gatta pressusa la fa i micétt orb.

La gatta frettolosa fa i micini ciechi

У торопливой кошки котята слепые.

Vèss adree a ongess i strivaj (Milano).

Essere al punto di ungersi gli stivali.

Начистить сапоги (быть готовым к отправлению, «сидеть на чемоданах»).

\section{Валле д'Аоста:}

Oeuf d'une heure, pain d'un jour, vin d'un an.

Uovo di un'ora, pane di un giorno, vino di un anno.

Яйцо одного часа, хлеб одного дня, вино одного года (т. е. самое лучшее).

Rouges muages à l'aurore de la pluie encore.

Nuvole rosse all'aurora pioggia ancora.

Красные облака на рассвете предвещают дождь. 


\section{Трентино Альто Адидже:}

Mac' sut, gran dapartut.

Maggio asciutto, grano dappertutto.

Сухой май - хороший урожай.

Volér star sora come l'òio.

Volere stare sopra come l'olio.

Хотеть быть сверху, как масло (хотеть командовать).

Венето:

Co te sì invità, bussa coi piè.

Quando sei invitato, bussa con i piedi.

Если ты приглашен в гости, стучи в дверь ногами (потому что руки заняты подарками).

Chi che no gà testa, gà gambe.

Chi non ha la testa, ha le gambe.

У кого нет головы, есть ноги (дурная голова ногам покоя не дает).

\section{Фриули Венеция Джулия:}

Al can de dó paróni al resta senza magnàr.

Il cane di due padroni rimane senza cibo.

Собака двух хозяев остается голодной (у семи нянек дитя без глазу).

\section{Лигурия:}

Loda ö mà ma stanni a cà.

Loda il mare ma stai a casa.

Хвали море, но оставайся на берегу.

Lontan da-i êuggi lontan da-o chèu.

Lontano dagli occhi lontano dal cuore.

С глаз долой - из сердца вон.

\section{Эмилия Романья:}

Nadel al sul e Pasqua stiss.

Natale con il sole, Pasqua nuvolosa.

Солнце на Рождество - облака на Пасху.

La prèscia bisàgna lassèrla al levri.

La fretta bisogna lasciarla alle lepri.

Спешку надо оставить зайцам.

\section{Тоскана:}

La diritta è serva della mancina.

La mano destra è al servizio della sinistra.

Правая рука - слуга левой.

La son di Prao e la vogl'essè rispettao.

Io son di Prato e voglio essere rispettato.

Я из Прато и потому требую уважения.

Умбрия:

Anghe la prèscia vòle lu tembu sua.

Anche la fretta ha bisogno di tempo.

Даже для спешки нужно время.

Artornà' ntoll'ovo.

Tornare nell'uovo.

Вернуться в яйцо (впасть в детство).

Марке: 
Allea li figlj tua puritti, se tu li voli ricchi e veneditti.

Alleva i tuoi figli poveretti, se li vuoi ricchi e benedetti.

Воспитывай своих детей, если хочешь их видеть счастливыми и богатыми.

'Na casa senza femmena è comme una linterna senza lume.

Una casa senza donna è come una lanterna senza lume.

Дом без женщины - все равно что фонарь без света.

Лацио:

La léngua nén té gl' uossa, ma fà glio fuosso.

La lingua non ha l'osso ma fa il fosso.

Язык не имеет костей, но может выкопать яму (язык без костей).

Masséra stàmo dé becco.

Stasera siamo di "bocca".

Сегодня мы приглашены на обед.

Абруццо:

Moje, marit e fije, coma ddi ti li da',ccusci'ti li pije

Moglie, marito e figli, come dio te li da', cosi'te li prendi

Жену, мужа и детей принимай такими, какими тебе дал их Бог.

Молизе:

U scarpare va senza scarpe.

Il calzolaio va senza scarpe.

Сапожник без сапог.

Кампания:

Tre so' li putienti: lo Papa, lo Rre e chi no tene nienti.

Tre sono i potenti: il Papa, il Re e chi non ha nulla.

Есть только трое самых могущественных: папа, король и нищий (тот, кому нечего терять).

Male e bbene a fina vene.

Sia il male che il bene finiscono.

И плохое, и хорошее заканчивается

Апулия:

U tiémb' s'é mmís' a lla v'rnín.

Il tempo si è messo "all'invernale".

Установилась зимняя погода.

Tèn' la lucért'l' a ddó kót'

Ha la lucertola a due code.

У него есть ящерица с двумя хвостами (о везучем человеке).

Базиликата:

Ognadunu porta l'acqua a u mulinu soio.

Ognuno porta l'acqua al suo mulino.

Каждый льет воду на свою мельницу.

U saziu nù'kkridi a lu dijunu.

Il sazio non crede al digiuno.

Сытый голодному не товарищ.

Калабрия

Quandu a jatta non c'esti 'u surici balla.

Quando non c'è la gatta il topo balla.

Когда нет кошки, мыши веселятся.

Si rispetta u cani po patruni. 
Si rispetta il cane, per rispetto del padrone!

Если уважаешь хозяина, уважай и его собаку

\section{Сицилия}

Megliu oi l'ovu ca dumani a gaddrina

Meglio oggi l'uovo che domani la gallina. небе).

Лучше яйцо сегодня, чем курица завтра (лучше синица в руках, чем журавль в

Mastro scarparo che sole scusute.

Il calzolaio con le suole delle scarpe scucite.

Сапожник в ботинках с оторвавшимися подошвами (сапожник без сапог).

\section{Сардиния}

Traballu inutili, traballu maccu.

Lavoro che non arreca utilità, lavoro pazzo.

Работа, не приносящая пользы - глупая работа.

Traballu continu bincit ogni cosa.

Il lavoro assiduo vince ogni cosa.

Терпенье и труд все перетрут.

Как видно из приведённых примеров, диалектальный вариант слова может немного отличаться, зачастую быть более коротким, чем в литературном варианте, но может и заменяться совершенно другим словом.

Для того, чтобы более полно представить себе языковую ситуацию в стране в целом, следует сказать, что наряду с диалектами используются и другие языки. Права языковых меньшинств в Италии защищены статьей 6 Конституции. В этот список официально входят 12 языков: фриульский, ладинский, немецкий, словенский, окситанский, французский, франко-провансальский, албанский, греческий, сардинский, каталанский и хорватский. Закон предусматривает использование этих языков в официальной документации, обучение им в школах, а также возможность создания радио- и телепрограмм на этих языках на центральных каналах. Кроме того, немецкий язык имеет равные права с итальянским в провинции Больцано, а французский - выступает на равных с итальянским в регионе Валле д’Аоста.

К сожалению, рамки учебной аудитории, как и рамки настоящей статьи, не позволяют в полной мере познакомить студентов и читателей с диалектальными особенностями итальянского языка, поэтому в аудитории изучается в основном литературная норма, знание которой дает возможность читать итальянскую прессу, слушать радио или смотреть телепередачи. Литературный язык, конечно, будет употреблён итальянцем, если его целью будет что-то объяснить иностранцу, не носителю языка. Однако, на наш взгляд, необходимо все же по возможности готовить студентов, изучающих итальянский язык, к тем диалектальным различиям, с которыми они могут столкнуться в будущем на практике, в рабочей поездке или во время отдыха, приехав в тот или иной регион Италии.

\section{СПИСОК ЛИТЕРАТУРЫ}

Рыжак, Н., Рыжак, Е. (2018) Итальянский язык. Самоучитель для тех, кто действительно хочет его выучить. М. : Эксмо. 608 с.

Дата поступления: 10.05.2020 г.

Гаврилова Юлия Викторовна - кандидат филологических наук, доцент, заведующий кафедрой иностранных языков Московского гуманитарного уни- 
верситета, член Общества истории изучения лингвистических идей имени Генри Суита. Адрес: 111395, Россия, г. Москва, у. Юности, д. 5. Тел.: +7 (916) 156-92-01. Эл. адрес: march1378@yandex.ru

Gavrilova Julia Viktorovna, Candidate of Philology, Associate Professor, Head, Department of Foreign Languages, Moscow University for the Humanities, Member, Henry Sweet Society for the History of Linguistic Ideas. Postal address: 5, Yunosti St., Moscow, Russian Federation, 111395. Tel.: +7 (916) 156-92-01. E-mail: march1378@yandex.ru

\section{Для цитирования:}

Гаврилова Ю. В. Краткий обзор диалектальной ситуации в Италии // Научные труды Московского гуманитарного университета. 2020. №3. C. 25-32. DOI: https://www.doi.org/10.17805/ trudy.2020.3.5 